\title{
Heteroscedasticity in perception of viewers of television advertisements: A comparative study on different age groups
}

\author{
Saurabh Grover \\ Assistant Professor, Khalsa College for Women, Amritsar, Punjab, India \\ *Corresponding Author: \\ Email: saurabhgrover1985@gmail.com
}

\begin{abstract}
Purpose: To analyze the portrayal of women in the advertisements and how respondents of different age react differently towards positive portrayal vs. Nudity in television advertisements.

Design/Methodology/Approach: The sample size of 1210 was taken for the study. The factors affecting attitudes of respondents below the age of 40 and above the age of 40 were found with the help of factor analysis and respondents were classified and distinguished with the help of cluster analysis and discriminant analysis.

Findings: Women in advertisements have been represented in illicit portrayal. She has not been shown in roles which represent her status and power. Men in commercials have been shown in roles superior to women. This leads to the lack of confidence among women. Major factors affecting attitude of people towards positive portrayal of women vs. nudity in advertisements were found out and listed as "Models over Products", "Feeling of Inferiority", "opposite attracts" etc. The respondents were classified as "Indifferent" and "Leveraged". These respondents were also differentiated using discriminant analysis. The study reveals the attitudes of the respondents on the basis of age towards the positive portrayal vs. Nudity in television advertisements and how women have been suffered due to the sensuous portrayal in the advertisements.
\end{abstract}

Keywords: Perception, Viewers, Television, Advertisements, Comparison, Age.

\section{Introduction}

Advertisements have a great impact on our day to day life. We say that stereotypes exist. But the question arises, who is the master mind behind this. As it can be seen that women have contributed immensely towards the society and the nation, but still the contribution made by them is overlooked. The reason behind this is the projection of women that people have in their minds and this projection has been the result of our so called Mass Media. We learn from what we see. If something is repeatedly shown to us every day through advertisements, what we will learn from them. But obvious it will influence us and will have a strong bearing on our mind.

This is the result that when we think of cleanliness or cooking or taking care of something, the first thing we relate that to is a woman because this is what commercials teach us. You can see any advertisement related to household chores or cleaning a product includes a woman. In a common advertisement related to a new "Surf Excel" washing detergent a mother in law told her daughter in law that washing would be easy now. This showed that washing is meant to be done by women only and she is solely responsible for the clean clothes of the family. Another advertisement of a "Hawkins" pressure cooker portrayed woman in the role of a cook, who is making delicious food for the whole family that depicts cooking is also a woman's task.

In the late $60 \mathrm{~s}$, a movement for the positive portrayal of women in advertisements was started. The feminist movement objects the way women have been portrayed in advertisements. It was also seen that women have been presented as a sexual object in advertisements. Considering an advertisement of a deodorant or a body soap, It can be seen that women have been projected half naked or in a sensual manner in order to attract the viewers. This representation of women was considered to be unnecessary and unethical. This portrayal leads to increased violence against women. Moreover it was objectified on the ground that advertisements do not depict true picture of a woman. She has been misrepresented that eventually effects her position and status in the society.

It was even seen that the way women have been projected in advertisements, is the way she has been treated in the society. If she is projected in submissive roles in advertisements, she will get those job profiles only and would not be able to get what she actually deserves.

\section{Theoretical Background}

Advertising has been considered as a paid promotion of a product in order to affect the buying behaviour of the viewers. As a source of information, it provides the necessary knowledge regarding the products. But this knowledge has been completely reciprocated with the unnecessary and unreasonable portrayal of women in advertisements. Advertisements considered to be responsible for the illicit portrayal of women. They portrayed women in advertisements in stereotypical roles. The women in advertisements have been shown as dependent on men, as housewives, as mothers or as care takers. They have been projected as responsible for household chores only. Women have been shown as meant to be at house only. Though the 
position of women has been changed over the period of time and she is equally participating in the economy as men. But still the struggle of women with the positive portrayal in advertisements has been going on since the inception of the advertising media.

A study looking at sex role stereotypes and their developmental aspects found that the acquisition of concepts about sex roles begins at an early age. By age three children can correctly apply gender labels and can correctly associate sex-typed objects like articles of clothing with the appropriate sex (Flerx, Fidler \& Rogers, 1976, p. 998). In another study by Broverman, Vogel, Clarkson and Rosenkrantz (1972) people were asked to define sex role stereotypes by defining the socially acceptable characteristics associated with gender. Milburn, Carney and Ramirez (2001) conducted a study where they examined the images of human beings in two popular clipart packages, Microsoft Office 97 and Print Shop Ensemble III for gender and racial equality. A content analysis was done in order to examine potential gender stereotyping. They found significant representational biases in both packages. Women were portrayed as underrepresented, and when depicted, both software packages portrayed them in a significantly different manner than males. Females were more likely to be shown as teenagers rather than as middle aged or elderly and were dressed in more revealing wardrobes. Males on the other hand were depicted as predominantly more active. Men were more likely to be depicted as authoritative and more knowledgeable. Women were more likely to be illustrated as submissive. For example, women were more likely to be shown in activities like sitting and men were depicted in activities like running. They concluded that stereotyping of women exists not only on television but other forms of communication as well.

Bardwick and Schumann (1967) analyzed male and female role portrayals in television commercials and concluded that women are portrayed primarily as housewives. Courtney and Whipple (1974) studied the portrayal of women in television commercials and found significant differences between men and women. Women were over-represented in advertisements for cosmetics and were less likely to appear in advertisements for cars, trucks and related products. Seventy-five percent of all advertisements using women were for products found in the kitchen or bathroom, 8 reinforcing the stereotype that a woman's place is in the home. Women as compared to men were portrayed mostly in house settings rather than business settings. Women did not make important decisions and lastly women were depicted as dependent on men and were regarded primarily as sexual objects. McArthur and Resko (1975) claimed that women were most likely to be defined not by occupational or other types of roles, but in roles that defined them in terms of their relationships with others, i.e. as spouse, girlfriend, parent or friend. They also found that women were depicted as product users in $86 \%$ of commercials and as product authorities in only 14 per cent of the advertisements, whereas men were portrayed in authoritative roles.

Nur Syuhada Mohd Radzi and Mahfuza (2017) revealed that the choice of words used by the advertisers in beauty advertisements to depict women does not show the true picture of women. If some advertisements portrayed women positively, those handful of advertisements are not sufficient. Mazuruse Mickson and Mrs. Musasa (2015) studied that Women in advertisements have been shown as obsessed with beauty, women as dependent for ultimate decisions on men, who has been engaged in small issues and unknowledgeable. But lecturers showed an opposite reaction towards the same. Kenew Gebreselassie (2015) concluded that in Ethiopian advertisements women have been portrayed in stereotypical roles. Women have also been shown in the roles where she is not required. Tazanfal Tehseem and Iqra Riaz (2015) revealed that Advertisers portray women negatively or in sensuous roles in order to increase their selling because the advertisement has been created in such a way that it showed that if you buy a particular product, it will add to your beauty and your personality.

Himashree Patowary (2014) conclude that media has not been showing any interest to change the position of women in the society. Media has not been taking any initiative to raise the voice against negative portrayal of women. Media has not been discussing any of the issues regarding women and the way she has been portrayed in advertisements. Christina N. Baker (2005) studied that in White oriented magazines related to women show 88 per cent of white women and magazines related to men, show 94 per cent of white women. Whereas only 6 per cent black women in women related magazines and 4 per cent black women in men related magazines were seen. Urich R. Orth and Denisa Holancova (2004) concluded that a particular sex role portrayal showed a strong emotional and attitudinal response towards that sex and the portrayals that showed a positive attitude towards female showed a negative attitude towards males and vice a versa.

Culley and Bennett (1976) noted that older women (50 years and older) were pictured with much less frequency than similarly aged men in television commercials from 1971 and 1974. Schneider and Schneider (1979) cited a subtle shift between 1971 and 1976 in the depictions of women in prime-time television commercials and a shift away from the portrayal of young women and toward that of women over 50. Bretl and Cantorís (1988) findings indicate several differences between the portrayal of men and women with many gaps narrowing after time. Men and women appeared equally more often as central figures in prime time commercials. Women appeared in occupational roles and men were presented as parents and spouses, with no other apparent occupation. Ford, 
Kramer Voli, Honeycutt and Casey (1998) conducted a study analysing Japanese magazines. It was concluded that Japanese magazines content did not depict the exact stereotypical role portrayals. A number of areas were there, where there is no significant differences between the gender role portrayals. Japanese Magazines portray both men and women in positive way. They showed men participated in household chores. Men were also shown with low priced product and women with high priced product. Milner and Collins (2000), conducted a study to examine how masculine and feminine countries differ in the way men and women portrayed in advertisements. It was found that male characters were more likely to be featured in relationships in feminine countries.

\section{Objectives of the Study}

To analyze the effect of age on the respondents attitude towards positive portrayal versus nudity in advertisements.

\section{Hypothesis for the Study:}

1. H01- There is no significant difference between the reactions of respondents with regard to their age as far as portrayal of women in the advertisements is concerned.

1. Ho2- All the respondents have similar attitude towards the positive portrayal vs. Nudity in advertisements or all respondents belong to only one cluster.

2. Ho3- There exist some characteristics that best discriminate among the different respondent group.

\section{Methodology}

The paper presents comprehensive model to explain variables regarding the attitudes of respondents towards positive portrayal vs. Nudity of women in advertisements. The data of 1210 respondents is collected from three commercially developed cities of Punjab region, India with the help of structured questionnaire. Equal respondents from three cities Amritsar, Jalandhar and Ludhiana are taken. In order to compare the attitude based on age, the equal numbers of respondents are taken from both categories i.e. Respondents above the age of 40 and Respondents below the age of 40 . Random sampling technique is being used to select the respondents. After analyzing the reliability using Cronbach's alpha method, other tools used are factor analysis, cluster analysis and discriminant analysis using SPSS.

\section{Data Analysis}

Out of 35 statements, five statements were removed as per the results of Cronbach's alpha method of checking reliability analysis. Exploratory factor analysis was conducted on 30 statements to explore the positive portrayal vs. Nudity of women in advertisements. Visual inspection for the data revealed that there are enough correlations among the statements to move ahead with the factor analysis. In Anti- image matrix, correlations are very low; hence data was ready to be used for factor analysis. KMO measure of sampling adequacy was computed and found to be 0.898 which is a good figure (Hair et.al 2011).

\section{Table 1: KMO and Bartlett's test of sphericity}

\begin{tabular}{|l|c|c|}
\hline \multicolumn{2}{|l|}{$\begin{array}{l}\text { Kaiser-Meyer-Olkin Measure of Sampling } \\
\text { Adequacy. }\end{array}$} & .898 \\
\hline $\begin{array}{l}\text { Bartlett's Test of } \\
\text { Sphericity }\end{array}$ & Approx. Chi-Square & 7394.061 \\
\hline & Df & 435 \\
\hline & Sig. & .000 \\
\hline
\end{tabular}

The value of Bartlett's test is found to be significant indicating that correlation matrix is not an identity matrix and value of chi square is also significant. Hence all these standards indicate that data is appropriate for factor analysis.

\section{Explanation to the derived Factors}

Factor 1- Urge to look like a Model: This is the most important factor that explained 21.717 per cent of the variance. It explains that the viewers wish to look like models in advertisements therefore people are encouraged to spend money on goods and services which are really not necessary. Moreover advertisers have created a mythical world through their advertisements that no one is ever ugly, poor, struggling or disabled.

Factor 2: Impact of Erotic Content: This factor accounted for the variance of 6.121 per cent of the variance. This shows that sexual appeal in the ads increase the attention of the viewers towards the model and not the product. Advertisements with erotic content appeal to feeling than to reasons.

Factor 3: Non Acceptance of Erotic Content: The third important factor accounts for 4.787 per cent of the variance. It explains that viewers find out the erotic content to be offensive. People say that the erotic content in advertisements is not fit to be watched with the family.

Factor 4: Models over Products: The fourth important factor accounts for 4.304 per cent of the variance. It shows that advertisers create confusion over product distinctions by diverting the attention towards models. The advertisers mainly prioritized on model rather than product. The advertisers believe that model can only be a stimulating factor to attract the viewers.

Factor 5: Feeling of Inferiority: The fifth factor accounts for 3.647 per cent of the variance. This factor explains the feeling of inferiority among viewers especially youngsters, who watch sexy models in advertisements and feel to have such shape and body size. They feel disrespectable of what they have and spend unnecessarily on cosmetic surgeries and dieticians. 
Factor 6: Opposite Attracts: The sixth factor accounts for 3.609 per cent of the variance. The advertisers are of the view that opposite genders attracts the viewers. Thus they advertise revealing models in advertisements to increase their sales.

Factor 7: Youngsters Accept Sensuous Portrayal: The seventh factor accounts for 3.384 per cent of the variance. This states that nowadays Nudity is considered as modernity. Youngsters accept the sensuous portrayal of women in advertisements.

\section{Cluster Analysis}

$\mathrm{H}_{02}$ All the respondents have similar attitude towards the positive portrayal vs. Nudity in advertisements or all respondents belong to only one cluster.

To test the hypothesis, cluster analysis has been applied on 1210 respondents. For the application of cluster analysis, firstly, hierarchical clustering is being done to find out how much clusters can be formed. It is explained with the help of Agglomeration Schedule. The Agglomeration Schedule helps to know about the cases being combined at each stage of a hierarchical clustering process. It is a procedure where clusters are formed by grouping objects into bigger and bigger clusters.

In Agglomeration Schedule the maximum difference lies between $2^{\text {nd }}$ last and 3rd last coefficients, so the number of clusters formed is two. The hypothesis set above is rejected as two clusters are formed, that means all the respondents do not belong to a single cluster.

Table 2: Distances between final cluster centres

\begin{tabular}{|l|c|c|}
\hline Cluster & $\mathbf{1}$ & $\mathbf{2}$ \\
\hline 1 & & 3.850 \\
\hline 2 & 3.850 & \\
\hline
\end{tabular}

This table shows the distances between the final cluster centres. It can be seen that the distance between Cluster 1 and Cluster 2 is 3.850 .

Table 3: Number of cases in each cluster

\begin{tabular}{|l|c|c|}
\hline Cluster & 1 & 599.000 \\
\hline & 2 & 611.000 \\
\hline Valid & 1210.000 & \multicolumn{1}{|}{} \\
\hline Missing & .000 & \multicolumn{1}{|c}{} \\
\cline { 1 - 2 } & &
\end{tabular}

The total respondents of 1210 were grouped into two clusters, namely cluster 1 and cluster 2 . Cluster 1 includes 599 respondents and Cluster 2 includes 611 respondents.
Table 4: Final cluster centres

\begin{tabular}{|c|c|c|}
\hline & \multicolumn{2}{|c|}{ Cluster } \\
\hline & $\mathbf{1}$ & $\mathbf{2}$ \\
\hline V1 & 2.97 & 3.95 \\
\hline V2 & 3.30 & 4.11 \\
\hline V3 & 3.10 & 3.56 \\
\hline V5 & 3.04 & 3.65 \\
\hline V6 & 2.89 & 3.59 \\
\hline V7 & 3.58 & 4.12 \\
\hline V9 & 2.86 & 3.43 \\
\hline V10 & 3.07 & 3.47 \\
\hline V11 & 2.85 & 3.47 \\
\hline V12 & 3.05 & 3.99 \\
\hline V13 & 3.02 & 3.49 \\
\hline V14 & 3.17 & 4.05 \\
\hline V16 & 3.03 & 3.91 \\
\hline V187 & 3.00 & 3.89 \\
\hline V198 & 2.85 & 3.38 \\
\hline V19 & 2.69 & 3.19 \\
\hline V20 & 2.95 & 3.34 \\
\hline V22 & 3.20 & 3.84 \\
\hline V23 & 2.89 & 3.90 \\
\hline V24 & 2.68 & 3.15 \\
\hline V25 & 2.81 & 3.38 \\
\hline V26 & 3.22 & 3.91 \\
\hline V28 & 2.82 & 3.77 \\
\hline V29 & 3.08 & 3.69 \\
\hline V30 & 2.56 & 2.92 \\
\hline V31 & 2.92 & 3.83 \\
\hline V32 & 2.87 & 3.29 \\
\hline V33 & 2.94 & 3.75 \\
\hline V34 & 3.25 & 4.01 \\
\hline V35 & 2.97 & 3.84 \\
\hline & & \\
\hline
\end{tabular}

Detailed Description of Clusters so Formed

Cluster 1: Indifferent: 599 respondents belong to this cluster. People in this cluster are very neutral. They are not very encouraged towards the positive portrayal of women nor they are offensive with the Bold or illicit portrayal of women. This shows that they don't ANOVA table clearly shows that there is no significant difference between the attitudes of the respondents of both the clusters. As this set of respondents is highly indifferent, thus marketers need not to consider them while making or reviewing any marketing strategy.

Cluster 2: Leveraged: In this cluster, 611 respondents are there. People in this cluster are leveraged. This shows that they think both ways. They are enthusiastic with the positive portrayal of women in advertisements and find the sexual portrayal of women offensive. They are of the view that compares who indulge in such unethical marketing practices should be boycott with.

\section{Discriminant Analysis}

Nowadays, it is not at all easy to determine the attitudes of respondents having different perceptions 
because no person is same and have different tastes. Thus their reactions towards different things are also different. An attempt has been made to study the attitudes of respondents towards positive portrayal of woman versus nudity in the advertisements. The respondents comprised of two different categories, respondents of age group of below 40 and respondents of age group of above 40 and factor scores so generated act as independent variables. Therefore, to identify such discriminating characteristics for the purpose of present study, discriminant analysis have been applied. The hypothesis for this category is:

\section{Hypothesis}

There exist some characteristics that best discriminate among the different respondent group.

Discriminant analysis is a classification problem, where two or more groups or clusters or populations are known a priori and one or more new observations are classified into one of the known populations based on the measured characteristics.

Table 5: Measurement of the overall fit of discriminant function

\begin{tabular}{|l|c|}
\hline \multicolumn{1}{|c|}{ Measures } & Function 1 \\
\hline Eigen value & .004 \\
\hline Percentage of Variance & $100 \%$ \\
\hline Cumulative Percentage of Variance & $100 \%$ \\
\hline Canonical Correlation & .061 \\
\hline Wilks' Lambda & .996 \\
\hline Chi Square & 4.488 \\
\hline Degrees of Freedom & 7 \\
\hline Significance & 0.722 \\
\hline
\end{tabular}

The Eigen value also called the characteristic root of each discriminant function, reflects the ratio of importance of dimensions which classify the cases of the dependent variables. There is one Eigen value for each discriminant function. The Eigen value of the function was derived as .004.
The relative percentage of a discriminant function equals a function's Eigen value divided by the sum of all Eigen values of all discriminant functions in the model. Thus it is Percentage of discriminating power for the model associated with a given discriminant function. As there is only one function, so it accounts for whole of the variance $(100 \%)$.

The canonical correlation, $\mathrm{R}$, is a measure of the association between the groups formed by the dependent and given discriminant function. The canonical correlation of each discriminant function is also the correlation of that function with the discriminant scores. As far as canonical correlation is concerned, it turned out to be .061 which means the model is able to explain most of the variance.

Wilks' Lambda tests the significance of each discriminant function specifically the significance of Eigen value for a given function. Value of Lambda varies from 0 to 1 . The value of Wilks' Lambda in this case is .996 which is in between 0 and 1 . Thus this value is indictor of the model being good.

Chi-square measures whether the two groups are significantly different or same. The value of chi- square also represents model being good. Our model is significant at $5 \%$ level of significance representing that there is a significant difference between two groups.

\section{Measurement of Strength of Relationships}

After measuring the fitness of discriminant function, the next step is to measure the predictive accuracy of the discriminant function. This measurement enables to check whether the discriminant function have adequate accuracy in the prediction of relationship or not.

A hold out sample is often used for validation of the discriminant function. This is a split halves test, a portion of the cases are assigned to the analysis sample for purpose of training the discriminant function, then it is validated by assessing its performance on the remaining cases in the hold out sample.

Table 6: Classification results ${ }^{\mathrm{a}}$

\begin{tabular}{|l|c|c|c|c|c|}
\hline \multirow{2}{*}{ Original } & \multirow{2}{*}{ Age } & \multicolumn{2}{|c|}{ Predicted Group Membership } & \multirow{2}{*}{ Total } \\
\cline { 3 - 5 } & & $\mathbf{1 . 0 0}$ & $\mathbf{2 . 0 0}$ & \\
& & & 312 & 293 & 605 \\
\cline { 3 - 6 } & & 1.00 & 294 & 311 & 605 \\
\cline { 3 - 6 } & 2.00 & 1.00 & 51.6 & 48.4 & 100.0 \\
\cline { 3 - 5 } & & 2.00 & 48.6 & 51.4 & 100.0 \\
\hline
\end{tabular}

The classification matrix specifying hit ratio has been shown in the table 5.64 in the present analysis, maximum chance criterion is 50 per cent that is $\left(605 / 1210^{*} 100\right)$. However as the hit ratio of the analysis sample 51.6 per cent is above the chance criterion of $50 \%$, it can be concluded that the discriminant model is valid. It can be seen from the table that 606 are predicted to be in group 1 but originally there are 312. Similarly 604 are predicted in group 2, but originally there are 311 cases. Thus it can be said that 587 are misclassified by the discriminant model thud giving a classification accuracy level of (623/1210*100) 51.48\%. 
Table 7: Discriminating scores

\begin{tabular}{|l|c|}
\hline Discriminating Variables & Function 1 \\
\hline Urge to look like Models & .633 \\
\hline Impact of erotic content & .157 \\
\hline Non acceptance of erotic content & .583 \\
\hline Models over Products & .121 \\
\hline
\end{tabular}

The independent variables "Urge to look like Models" and "Non acceptance of Erotic content" are able to discriminate two groups to a large extent. The two groups have different perception towards urge to look like models and non acceptance of erotic content. It may be due to the fact that elder respondents do not wish to look like models as far as young respondents are concerned and elder respondents don't accept erotic content so easily in the advertisements. Other three variables are not able to discriminate two groups and their loadings are also very less.

\section{Conclusions}

The investigation of stereotypical role portrayal of women has contributed much to the analysis. It can be seen that all these researches help women to be portrayed in positive roles to some extent. But still the changes seen are negligible.

The factor analysis showed various factors that revealed about the behaviour of the respondents. These factors include, urge to look like a model in which viewers wish to have similar looks as models. Thus they spend unnecessarily on cosmetic surgeries. The impact of erotic content leads to violence against women. Because of such content, teenagers foster sexuality. The viewers do not accept such content and found it to be offensive. They feel that such content is not fit to be watched with the family. But advertisers, in order to earn higher profits, choose models over products. The factor analysis showed that women are not satisfied with the size and shape of body they have and they are keen of getting what size and shape models have. In order to be as fit as them, they follow strict diets. The independent variables "Urge to look like Models" and "Non acceptance of Erotic content" are able to discriminate two groups to a large extent. The two groups have different perception towards urge to look like models and non acceptance of erotic content. It may be due to the fact that elder respondents do not wish to look like models as far as young respondents are concerned and elder respondents don't accept erotic content so easily in the advertisements.
In conclusion, it is apparent that women have been predominantly shown as mothers or happy housewives. This is true enough, but the thing is this is not the only role woman is playing these days. She has become independent, is working, is participating in the affairs of the business and economy. Thus these roles should also be considered by the advertisers while portraying them in television advertisements.

\section{References}

1. Bardwick, J. M., \& Schumann, S. I. (1967). Portrait of American men and women in TV commercials. Psychology. 1967;4(4):18-23.

2. Broverman, I. K., Vogel, S. R., Broverman, D. M., Clarkson, F. E., \& Rosenkrantz, P. S. Sex-role stereotypes: A current appraisal. Journal of Social issues. 1972;28(2):59-78.

3. Courtney, A. E., \& Whipple, T. W. Women in TV commercials. Journal of Communication. 1974;24(2):110-118.

4. Culley, J. D., \& Bennett, R. Selling women, selling blacks. Journal of Communication. 1976;26(4):160-174.

5. Flerx, V. C., Fidler, D. S., \& Rogers, R. W. Sex role stereotypes: Developmental aspects and early intervention. Child Development. 1976:998-1007.

6. Ford, J. B., Voli, P. K., Honeycutt Jr, E. D., \& Casey, S. L. Gender role portrayals in Japanese advertising: A magazine content analysis. Journal of Advertising. 1998;27(1):113-124.

7. McArthur, L. Z., \& Resko, B. G. The portrayal of men and women in American television commercials. The Journal of Social Psychology. 1975;97(2):209-220.

8. Mickson, M., \& Tendero, M. M. (2015). A Critical Evaluation of the Portrayal of Zimbabwean Women in Advertisements and its Impact on Shona Culture.

9. Milburn, S. S., Carney, D. R., \& Ramirez, A. M. Even in modern media, the picture is still the same: A content analysis of clipart images. Sex roles. 2001:44(5);277-294.

10. Milner, L. M., \& Collins, J. M. (2000). Sex-role portrayals and the gender of nations. Journal of Advertising, 29(1), 67-79.

11. Orth, U. R., \& Holancova, D. Men's and women's responses to sex role portrayals in advertisements. International Journal of Research in Marketing . 2004;21(1);77-88.

12. Patowary, H. Portrayal of Women in Indian Mass Media: An Investigation. Journal of Education \& Social Policy, 2014;1(1):84-92.

13. Radzi, N. S. M., \& Musa, M. Beauty Ideals, Myths and Sexisms: A Feminist Stylistic Analysis of Female Representations in Cosmetic Names. GEMA Online ${ }^{\circledR}$ Journal of Language Studies, 2017;17(1).

14. Schneider, K. C., \& Schneider, S. B. Trends in sex roles in television commercials. The Journal of Marketing. 1979;79-84. 